\title{
Processing and Microstructural Characterization of a Ti-Cr-Nb Alloy Synthesized by High-Energy Ball-Milling
}

\author{
José Fernando Ribeiro de Castro ${ }^{a *}$, Sydney Ferreira Santos ${ }^{\mathrm{b}}$, Tomaz Ishikawa ${ }^{\mathrm{a}}$, Walter José Botta

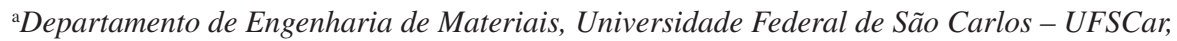 \\ Rod. Washington Luis, Km 235, CEP 13565-905, São Carlos, SP, Brazil \\ ${ }^{\mathrm{b}}$ Centro de Engenharia, Modelagem e Ciências Sociais Aplicadas - CECS, \\ Universidade Federal do ABC - UFABC, \\ Rua Santa Adélia, 166, CEP 09210-170, Santo André, SP, Brazil
}

Received: December 7, 2011; Revised: February 15, 2012

\begin{abstract}
Ti-based body centered cubic (BCC) solid solutions are promising materials for hydrogen storage. These alloys are usually synthesized by melting processes and have large amounts of vanadium as alloying element to stabilize the BCC phase at room temperature. In this work high energy ball-milling was evaluated as processing route for a $\mathrm{Ti}$ - based $\mathrm{BCC}$ solid solution. Moreover, the feasibility of $\mathrm{Nb}$ as stabilizer for the BCC phase is also investigated. The results show that the BCC phase is rapidly formed by ball-milling. After 2 hours of milling the alloy is mainly composed by BCC phase. Moreover, the time of milling must be limited in order to minimize the contamination with iron promoted by the wearing of milling balls and vials.
\end{abstract}

Keywords: hydrogen storage materials, metal hydrides, Ti - based bcc solid solution

\section{Introduction}

Investigations on metal hydrides for hydrogen storage have been attracting much attention over the last decades due to economical and environmental issues ${ }^{1,2}$. The desirable material for such application should satisfy a number of requirements, namely: high gravimetric storage capacity, low cost, availability, and capacity to absorb and release hydrogen at moderate temperature and pressure ${ }^{2}$. Nowadays, there is a number of hydride forming alloys which have been investigated for hydrogen storage. Among others, Ti alloys are very promising candidates due to their light weight, availability and low temperature of hydride formation/decomposition ${ }^{3-7}$. The most interesting Ti alloys for hydrogen storage applications are those with body-centered cubic (BCC) crystal structures. These alloys are BCC solid solutions usually synthesized by arc-melting and have their hydrogen storage properties measured in as-cast state. Moreover, the investigated alloys typically have large amounts of vanadium metal in their compositions, which is an expensive raw material ${ }^{5,6}$. This element improves the hydrogen storage capacity of the alloys and also stabilizes the BCC phase at room temperature which is stable only at high temperatures in the $\mathrm{Ti}$ - $\mathrm{Cr}$ phase diagram ${ }^{8}$. The aim of the present study was to investigate the synthesis of a Ti - based BCC solid solution by high energy ball-milling and also to evaluate the feasibility of using $\mathrm{Nb}$ as $\mathrm{BCC}$ phase stabilizer.

\section{Material and Methods}

The investigated alloys were produced by high energy ball-milling using a Fritsch P6 centrifugal mill under Ar

*e-mail: jfrcastro@gmail.com atmosphere. All millings were carried out using a ball to powder weight ratio of 30:1 and milling speed of $600 \mathrm{rpm}$. The $\mathrm{Ti}_{33} \mathrm{Cr}_{33} \mathrm{Nb}_{33}$ alloy was synthesized using high purity metal powders as raw materials (+99\%). After milling, the samples were manipulated in an Ar-filled glove-box in order to minimize the oxidation.

After milling, the samples were characterized by X-ray diffraction, using a Siemens D5005 difractometer $(\mathrm{Cu} \mathrm{K \alpha}$ radiation), transmission electron microscopy, using a Philips CM-120 microscope with $\mathrm{LaB}_{6}$ filament and operating at $120 \mathrm{kV}$, and scanning electron microscopy, using a Philips XL-30 microscope.

\section{Results and Discussion}

Figure 1 shows the XRD patterns of the $\mathrm{Ti}_{33} \mathrm{Cr}_{33} \mathrm{Nb}_{33}$ alloy after 2, 4, 6, and 8 hours of milling. The diffraction peaks of the BCC solid solution were identified. Another peak probably due to $\mathrm{Cr}$ was detected. But it is important to note that $\mathrm{Cr}$ and $\mathrm{Fe}$ diffraction peaks are very close and it is not possible to disregard Fe contamination during milling.

The position of the main peak of the BCC solid solution suggests changes in lattice cell parameter as function of milling time. For 4 hours of milling, this peak shift to lower diffraction angles indicating an increase of the cell parameter while further milling promoted shift to higher angles indicating decrease in cell parameter. The main reason for this behavior can be the incorporation of the alloying elements to the BCC solution. There is no detectable peak of $\alpha$-Ti in these patterns which is probably due to a faster 


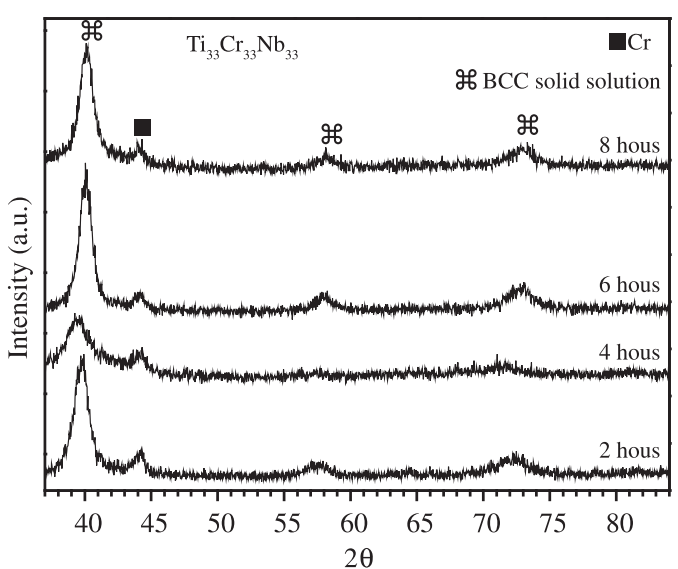

Figure 1. XRD patterns of the ball-milled $\mathrm{Ti}_{33} \mathrm{Cr}_{33} \mathrm{Nb}_{33}$ alloy after different milling times.

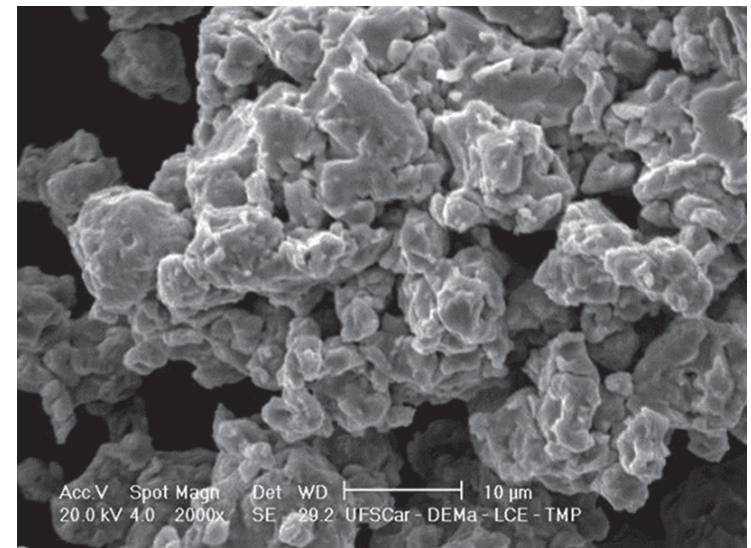

Figure 2. SE-SEM image of the $\mathrm{Ti}_{33} \mathrm{Cr}_{33} \mathrm{Nb}_{33}$ alloy after 8 hours of milling.

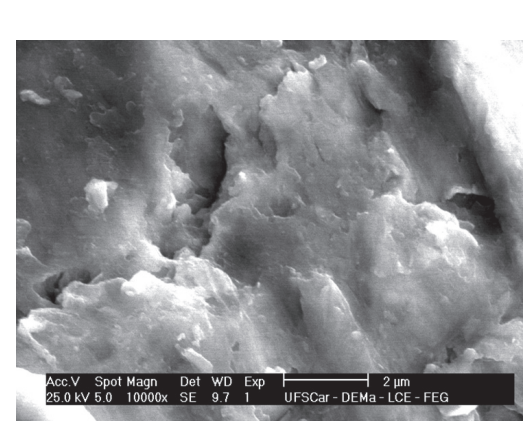

(a)

$\mathrm{CrKa}, 11$

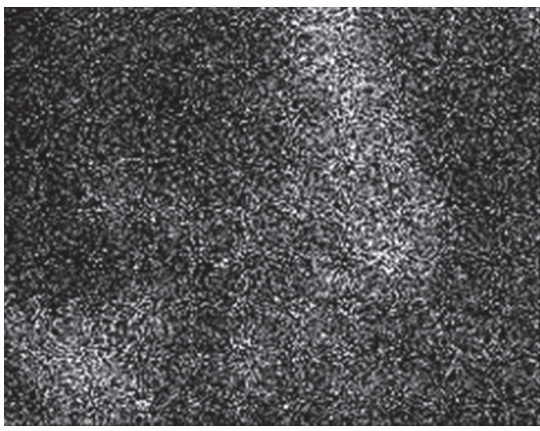

(d)

\section{NbLa1, 12}

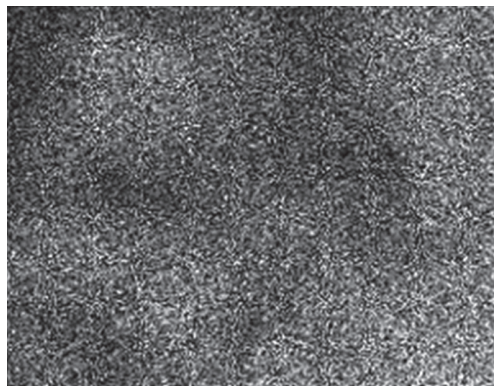

(b)
TiKa, 12

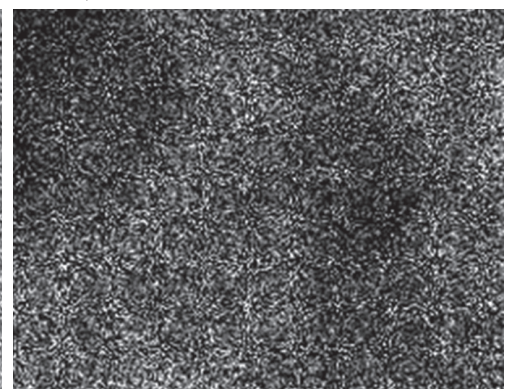

(c)

- $\mathrm{FeKa}, 4$

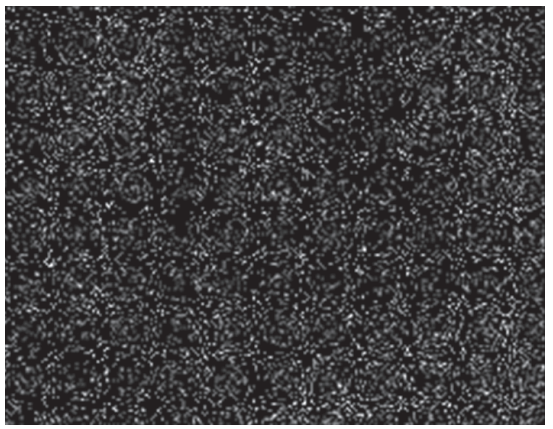

(e)

Figure 3. SEM-SE image for the $\mathrm{Ti}_{33} \mathrm{Cr}_{33} \mathrm{Nb}_{33}$ alloy after 2 hours of milling (a) and the corresponding EDX compositional maps of $\mathrm{Nb}(\mathrm{b}), \mathrm{Ti}(\mathrm{c}), \mathrm{Cr}(\mathrm{d})$, and $\mathrm{Fe}(\mathrm{e})$.

incorporation of this element to $\mathrm{Nb}$ structure. Conversely, a remaining peak of $\mathrm{Cr}$ is detectable in all diffraction patterns which suggest a slower incorporation of this element which has the smallest atomic volume or contamination with Fe. For short milling time, it is unlikely a significant contamination with $\mathrm{Fe}$ but for longer milling times the abrasive wear promoted by hard BCC phase particles can lead to a extensive contamination with $\mathrm{Fe}$, as observed for high energy ball-milling of a Ti-Cr-V cast alloy ${ }^{9}$.

Figure 2 shows the scanning electron microscopy image in secondary electron mode (SEM-SE) of the alloy milled by 8 hours. The powder's morphology is composed of large agglomerates of cold welded particles, formed by a ductile-ductile alloying mechanism ${ }^{10}$.

In order to analyze the chemical homogeneity of the samples and evaluate on Fe contamination, the samples milled for shorter and longer milling times were analyzed by Energy-dispersive X-ray spectroscopy (EDX). As expected, there is an effect of time of milling on the Fe contamination. For 2 hours of milling the average content of Fe was only 1.6 at $\%$ while after 8 hours of milling this amount increased to about 12 at $\%$. The substantial 
NbLa1, 18

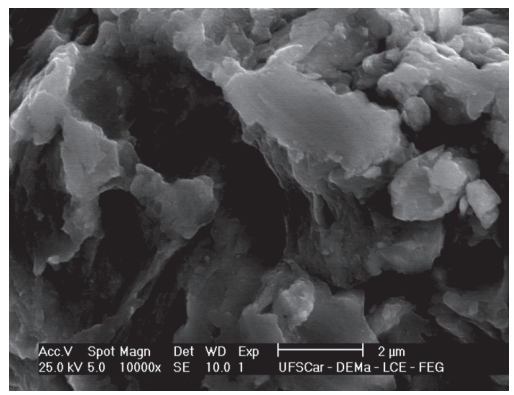

(a)

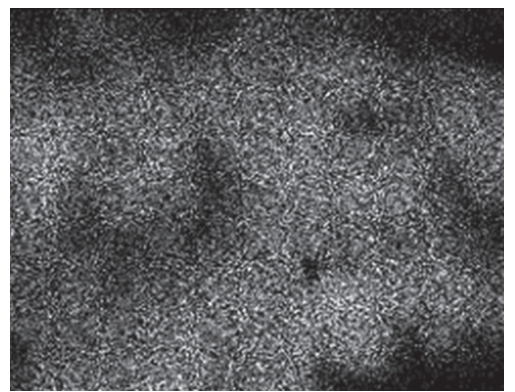

(b)
TiKa, 13

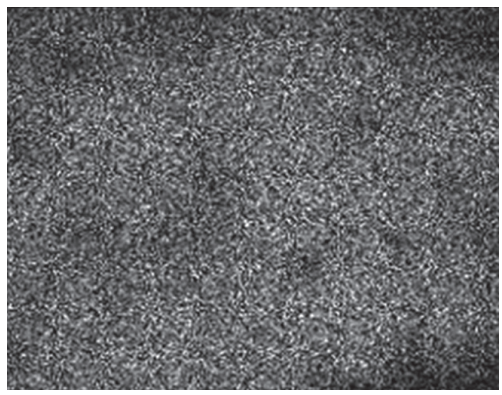

(c)

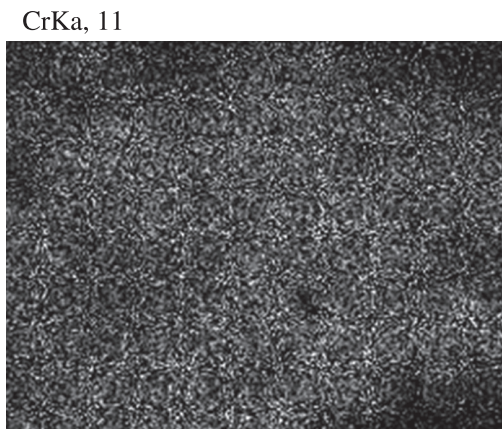

(e)
FeKa, 15

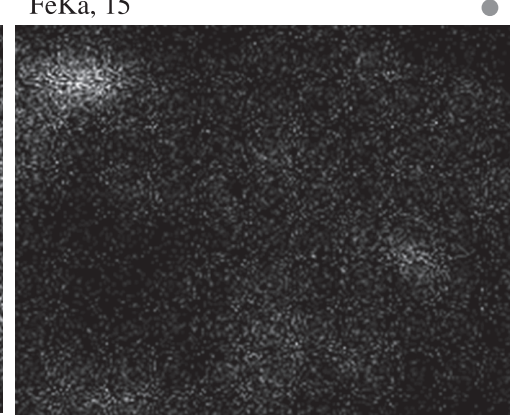

(d)

Figure 4. SEM-SE image for the $\mathrm{Ti}_{33} \mathrm{Cr}_{33} \mathrm{Nb}_{33}$ alloy after 8 hours of milling (a) and the corresponding EDX compositional maps of $\mathrm{Nb}(\mathrm{b}), \mathrm{Ti}(\mathrm{c}), \mathrm{Cr}(\mathrm{d})$, and $\mathrm{Fe}(\mathrm{e})$.

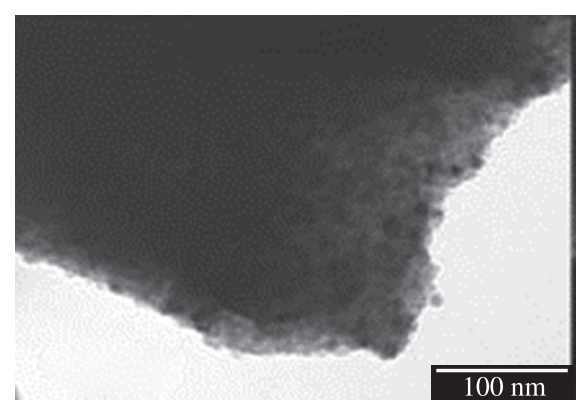

(a)

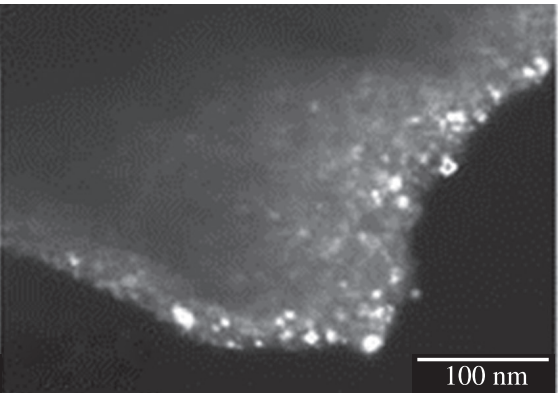

(b)

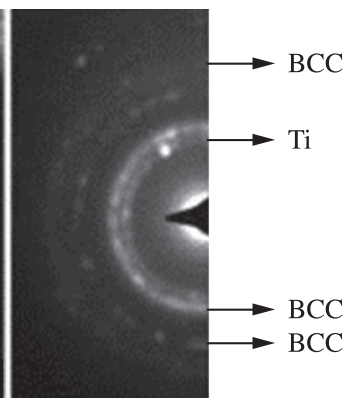

(c)

Figure 5. BF (a) and DF (b) images and the corresponding SAEDP (c) of the $\mathrm{Ti}_{33} \mathrm{Cr}_{33} \mathrm{Nb}_{33}$ alloy after 8 hours of milling.

increase on Fe contamination can be explained by the fast formation of the BCC solid solution, observed on the XRD patterns. This BCC phase is very hard when compared to the pure metallic elements, thus leading to an excessive wear of the milling balls and vial, as previously commented ${ }^{9}$.

Concerning the chemical homogeneity of the samples, Figures 3 and 4 show the compositional maps (EDX mapping) for the alloying elements and iron after 2 and 8 hours of milling, respectively. These results indicate a homogeneous distribution of the alloying elements over the microstructure. In the case of Fe, after 8 hours of milling this contaminant is concentrate in some regions of the microstructure probably due to the fragmentation of some small particles from the milling devices.
Figure 5 shows the TEM images in bright field (a) and dark field modes (b), and the associated selected area electron diffraction pattern - SAEDP (c) of the $\mathrm{Ti}_{33} \mathrm{Cr}_{33} \mathrm{Nb}_{33}$ alloy after 8 hours of ball-milling. From these results, it is clearly observed the nanocrystalline structure of the sample with homogeneous crystallite size of nearly $17 \mathrm{~nm}$. The SAEDP was indexed and indicated the presence of BCC solution and Ti phases. Both SAEDP and XRD patterns are consistent with a microstructure composed mainly by BCC solid solution phase and some residue of unalloyed metallic elements.

\section{Conclusions}

High-energy ball-milling of pure elements showed to be an effective processing route to synthesize the Ti-based 
$\mathrm{BCC}$ solid solution in the alloy with equiatomic composition of $\mathrm{Ti}, \mathrm{Nb}$, and $\mathrm{Cr}$.

Niobium successfully acted as stabilizer for the BCC crystal structure showing to be an interesting candidate to replace vanadium in this type of alloys.

The Fe contamination is a main task for the synthesis of such Ti-based BCC alloys by ball-milling and short milling times must be employed in order to prevent excessive contamination. The fast kinetic of formation of the BCC phase in this alloy permits to obtain a fully BCC structure after short milling time. Moreover, the adoption of shorter milling times is also interesting in order to reduce the

\section{References}

1. Bérubé V, Radtke G, Dresselhaus M and Chen G. Size effects on the hydrogen storage properties of nanostructured metal hydrides: a review. International Journal of Energy Research. 2007; 31:637-663. http://dx.doi.org/10.1002/ er. 1284

2. Santos SF, Ishikawa TT and Ticianelli EA. Fundamentals and technological applications of hydrogen - absorbing Mg amorphous alloys. In: Telle JR and Pearlstine NA, editors. Amorphous Materials: Research, Technology and Applications. New York: Nova Science Publishers Inc.; 2009. p. 219-237.

3. Challet $\mathrm{S}$, Latroche $\mathrm{M}$ and Heurtaux F. Hydrogenation properties and crystal structure of the single BCC $\left(\mathrm{Ti}_{0.355} \mathrm{~V}_{0.647}\right)_{100-\mathrm{x}} \mathrm{M}_{\mathrm{x}}$ alloys with $\mathrm{M}=\mathrm{Mn}, \mathrm{Fe}, \mathrm{Co}, \mathrm{Ni}(\mathrm{x}=7,14$ and 21). Journal of Alloys and Compounds. 2007; 31:249-301. http://dx.doi. org/10.1016/j.jallcom.2006.08.070

4. Shibuya M, Nakamura J, Enoki H and Akiba E. High-pressure hydrogenation properties of Ti-V-Mn alloy for hybrid hydrogen storage vessel. Journal of Alloys and Compounds. 2009; 475:543-545. http://dx.doi.org/10.1016/j. jallcom.2008.07.121 contamination with $\mathrm{Fe}$. The longer milling times promotes excessive wear of the milling tools (steel balls and vial), resulting in excessive contamination of the alloy with Fe. Thus, optimizing the milling time it is possible to obtain both a fully BCC structure and a limited contamination with Fe.

The microstructure of the investigated alloy indicates that it is conceivable candidate for hydrogen storage applications.

\section{Acknowledgements}

The authors would like to thanks the financial support from $\mathrm{CNPq}$ and FAPESP.
5. Santos SF and Huot J. Hydrogen storage in Ti-Mn(FeV) BCC alloys. Journal of Alloys and Compounds. 2009; 480:5-8. http:// dx.doi.org/10.1016/j.jallcom.2008.09.191

6. Santos SF and Huot J.Hydrogen storage in TiCr1.2(FeV)x BCC solid solutions. Journal of Alloys and Compounds. 2009; 472:247-251. http://dx.doi.org/10.1016/j.jallcom.2008.04.062

7. Amira S, Santos SF and Huot J. Hydrogen sorption properties of Ti-Cr alloys synthesized by ball milling and cold rolling. Intermetallics. 2010; 18:140-144. http://dx.doi.org/10.1016/j. intermet.2009.07.004

8. Lee JY, Kim JH, Park SI and Lee HM. Phase equilibrium of the Ti-Cr-V ternary system in the non-burning $\beta$-Ti alloy region. Journal of Alloys and Compounds. 1999; 291:229-238. http:// dx.doi.org/10.1016/S0925-8388(99)00144-9

9. Santos SF, Costa ALM, De Castro JFR, Dos Santos DS, Botta WJ and Ishikawa TT. Mechanical and reactive milling of a TiCrV BCC solid solution. Journal of Metastable and Nanocrystalline Materials. 2004; 20-21:291-296. http://dx.doi. org/10.4028/www.scientific.net/JMNM.20-21.291

10. Suryanarayana C. Mechanical alloying and milling. Progress in Materials Science. 2001; 46:1-184. http://dx.doi.org/10.1016/ S0079-6425(99)00010-9 